\title{
High prevalence of Cfr-producing Staphylococcus species in retail meat in Guangzhou, China
}

\author{
Zhen-Ling Zeng ${ }^{1 \dagger}$, Hong-Kun Wei ${ }^{1 \dagger}$, Jing Wang ${ }^{1 \dagger}$, Da-Chuan Lin², Xiao-Qin Liu and Jian-Hua Liư ${ }^{1 *}$
}

\begin{abstract}
Background: The emergence and wide distribution of the transferable gene for linezolid resistance, cfr, in staphylococci of human and animal origins is of great concern as it poses a serious threat to the public health. In the present study, we investigated the emergence and presence of the multiresistance gene, cfr, in retail meat sourced from supermarkets and free markets of Guangzhou, China.

Results: A total of 118 pork and chicken samples, collected from Guangzhou markets, were screened by PCR for cfr. Twenty-two Staphylococcus isolates obtained from 12 pork and 10 chicken samples harbored cfr. The 22 cfr-positive staphylococci isolates, including Staphylococcus equorum $(n=8)$, Staphylococcus simulans $(n=7)$, Staphylococcus cohnii $(n=4)$, and Staphylococcus sciuri $(n=3)$, exhibited 17 major Smal pulsed-field gel electrophoresis (PFGE) patterns. In 14 isolates, cfr was located on the plasmids. Sequence analysis revealed that the genetic structures (including $\triangle \operatorname{tnp} A$ of Tn558, IS21-558, $\Delta \operatorname{tnp} B$, and tnpC of Tn558, orf138, fexA) of cfr in plasmid pHNTLD18 of a S. sciuri strain and in the plasmid pHNLKJC2 (including rep, $\Delta$ pre/mob, cfr, pre/mob and partial ermC) of a S. equorum strain were identical or similar to the corresponding regions of some plasmids in staphylococcal species of animal and human origins.

Conclusions: To the best of our knowledge, this is the first study to report the presence of the multiresistance gene, cfr, in animal meat. A high occurrence of $\mathrm{cfr}$ was observed in the tested retail meat samples. Thus, it is important to monitor the presence of cfr in animal foods in China.
\end{abstract}

Keywords: Plasmids, Linezolid, Staphylococcus spp, Food safety, Resistance epidemiology

\section{Background}

Linezolid is considered to as the last treatment option for infections caused by methicillin-resistant Staphylococcus aureus (MRSA), vancomycin-resistant Enterococci and penicillin-resistant Streptococcus [1]. Mutations in the drug target site (23S rRNA or ribosomal proteins L3 and L4) are the most common mechanisms of linezolid resistance. Due to the low frequency of target mutation, the frequency of linezolid resistance is also relatively low [2]. However, emergence of the transferable linezolid resistance gene, $c f r$, in clinical isolates poses a challenge in linezolid treatment. $c f r$ gene encodes an RNA methyltransferase, which modifies the adenine residue at position 2503 of the 23S rRNA gene and thereby confers resistance to phenicols, lincosamides, oxazolidinones, pleuromutilins,

\footnotetext{
* Correspondence: jhliu@scau.edu.cn

${ }^{\dagger}$ Equal contributors

'College of Veterinary Medicine, National Reference Laboratory of Veterinary Drug Residues (SCAU), South China Agricultural University, Guangzhou, China Full list of author information is available at the end of the article
}

and streptogramin A antibiotics (the $\mathrm{PhLOPS}_{\mathrm{A}}$ phenotype) as well as decreases susceptibility to the 16-membered macrolides spiramycin and josamysin [3-5].

Since its first detection from a bovine Staphylococcus sciuri isolate in 1997 [6], cfr has been globally transmitted among different bacteria, such as Staphylococcus spp., Enterococcus spp., Macrococcus spp., Jeotgalicoccus spp., Streptococcus suis, Escherichia coli, Bacillus spp., Proteus vulgaris $[7,8]$. This gene is widely distributed in the isolates of both human and animal origin, especially in China [8]. A recent study has described this gene in farm environments [9]. However, there has been no study on the distribution of $c f r$ in retail meat. In the present study, we investigated the presence and the genetic background of this multiresistance gene in retail meat samples sourced from supermarkets and free markets of Guangzhou, China.

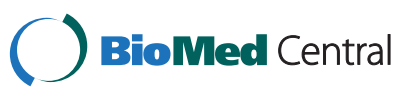

(c) 2014 Zeng et al.; licensee BioMed Central Ltd. This is an Open Access article distributed under the terms of the Creative Commons Attribution License (http://creativecommons.org/licenses/by/4.0), which permits unrestricted use, distribution, and reproduction in any medium, provided the original work is properly credited. The Creative Commons Public Domain Dedication waiver (http://creativecommons.org/publicdomain/zero/1.0/) applies to the data made available in this article, unless otherwise stated. 


\section{Results}

Identification of cfr-positive Staphylococcus isolates

Of the 118 retail meat samples tested, a total of 22 cfr-positive Staphylococcus isolates were detected in 12 pork samples and 10 chicken samples. The 22 cfr-positive staphylococcal isolates included Staphylococcus equorum $(\mathrm{n}=8)$, Staphylococcus simulans $(\mathrm{n}=7)$, Staphylococcus cohnii $(\mathrm{n}=4)$, and Staphylococcus sciuri $(\mathrm{n}=3)$. In addition, one cfr-positive Macrococcus caseolyticus isolate was obtained from a chicken sample. In total, 15.8\% and $26.2 \%$ pork and chicken samples carried cfr-positive isolates, respectively.

\section{Clonal analysis of cfr-positive staphylococci and location of $c f r$}

Pulsed-field gel electrophoresis (PFGE) of 22 cfr-positive staphylococci revealed 17 major SmaI PFGE patterns (Table 1). Eight $S$. equorum isolates showed five different PFGE patterns, with two chicken strains from the same market presenting indistinguishable patterns. Six distinct PFGE patterns were identified for the seven S. simulans isolates, with only two pork isolates from different markets presenting similar PFGE patterns. For the four $S$. cohnii isolates, three PFGE patterns were identified, with two pork isolates from the same market presenting identical patterns. Each of the three $S$. sciuri isolates exhibited distinct PFGE patterns. In summary, most of the cfr-positive staphylococcal isolates were genetically distinct, but a clonal transfer of cfr-positive staphylococcal isolates had occurred either in the same or among different markets.

Results of Southern blotting indicated that 14 isolates harbored $c f r$ in their plasmid DNA (Table 1). The remaining eight isolates appeared to carry $c f r$ in their genomic DNA; however, this assumption needs to be further confirmed by S1-PFGE. Only one cfr-carrying plasmid (designated as pHNLKJC2) that originated from a chicken isolate, TLKJC2, was transformed into Staphylococcus aureus RN4220. The transformant was confirmed by polymerase chain reaction (PCR) for $c f r$; it showed the same PFGE pattern as that of Staphylococcus aureus RN4220.

\section{Antimicrobial susceptibility of cfr-positive Staphylococcus isolates and the transformants}

All of the 22 cfr-positive staphylococcal isolates had elevated minimum inhibitory concentrations (MICs) against chloramphenicol (16 to $>64 \mathrm{mg} / \mathrm{L}$ ), florfenicol (32 to $>64 \mathrm{mg} / \mathrm{L}$ ), clindamycin ( $\geq 64 \mathrm{mg} / \mathrm{L})$, tiamulin $(64$ to $>128 \mathrm{mg} / \mathrm{L})$, valnemulin $(0.5$ to $>64 \mathrm{mg} / \mathrm{L}$ ), and linezolid ( 2 to $16 \mathrm{mg} / \mathrm{L}$ ) (Table 1). In addition, 18, 14, 13, 17, 6, and 17 isolates exhibited resistance to oxacillin, ciprofloxacin, gentamicin, erythromycin, rifampicin, and tetracycline, respectively. All isolates were found to be susceptible to vancomycin.
Compared with S. aureus RN4220, the transformant carrying pHNLKJC2 had elevated MICs against chloramphenicol (8-fold), florfenicol (16-fold), clindamycin (64-fold), tiamulin (32-fold), valnemulin (32-fold), and linezolid (4-fold) (Table 1), supporting the presence and the functional activity of $c f r$. In addition, the transformant carrying pUC18-cfr exhibited 2-fold-elevated MICs for chloramphenicol and florfenicol as compared to E. coli DH5a.

\section{Analysis of the genetic environment of $c f r$ in the plasmid pHNTLD18 and pHNLKJC2}

Southern blotting confirmed that, in Staphylococcus equorum TLD18, cfr was located on a plasmid designed as pHNTLD18. An approximately 5.7-kb EcoRI fragment containing cfr was cloned and sequenced. A Tn558 variant was identified on the plasmid pHNTLD18, in which parts of the Tn558-associated transposase genes tnpA and $\operatorname{tn} p \mathrm{~B}$ were replaced by a $c f$-carrying segment and the insertion sequence IS21-558 (Figure 1A). Another resistance gene, $f e x A$, encoding an exporter that mediates the active efflux of phenicols, was found to be located downstream of $\operatorname{Tn} 558$.

The sequences 1,926-bp upstream and 2,659-bp downstream of $c f r$ on the plasmid pHNLKJC2 were obtained by primer walking. Basic local alignment search tool (BLAST) analysis of these sequences revealed a $3{ }^{\prime}$ truncated segment of the gene pre/mob upstream of $c f r$. Further upstream, an incomplete rep gene was detected. Analysis of the region downstream of $c$ fr revealed the presence of a complete pre/mob gene. Immediately downstream of the pre/mob gene, an incomplete macrolide-lincosamide-streptogramin $\mathrm{B}\left(\mathrm{MLS}_{\mathrm{B}}\right)$ resistance gene erm C was detected (Figure 1B).

\section{Discussion}

Lack of previous studies on the distribution of the multiresistance gene $c f r$ among staphylococci in retail meat led us to screen 118 meat samples for the same. In our analysis, cfr was detected in 22 samples. The detection rate was $18.6 \%$, which is higher than the detection rates of food animal samples in China [10,11]. The low fitness cost of $c f r$ acquisition observed in staphylococcal isolates may account for the persistence of this multiresistance gene in retail meat even in the absence of an antimicrobial selection pressure [12]. The high detection rate found in this study suggested that $c f r$ may be widely disseminated among staphylococci in the meats sold in China, increasing the possibility of this gene entering the food chain.

In this study, S. equorum $(\mathrm{n}=8)$ was the predominant species among the 22 cfr-carrying isolates obtained from animal food sources. To the best of our knowledge, this is the first report of $c f r$ in S. equorum. S. equorum was originally isolated from the skin of horses and was later 
Table 1 Characteristics of cfr-carrying isolates and transformants

\begin{tabular}{|c|c|c|c|c|c|c|c|c|c|c|c|c|}
\hline \multirow[t]{2}{*}{ Isolate } & \multirow[t]{2}{*}{$\begin{array}{l}\text { Staphylococcal } \\
\text { species }\end{array}$} & \multirow[t]{2}{*}{ Origin } & \multirow[t]{2}{*}{ Market } & \multirow[t]{2}{*}{$\begin{array}{l}\text { PFGE } \\
\text { type }^{a}\end{array}$} & \multirow[t]{2}{*}{$\begin{array}{l}\text { Location } \\
\text { of } c f r^{\mathrm{b}}\end{array}$} & \multicolumn{6}{|c|}{$\begin{array}{l}\text { MIC values of antimicrobial } \\
\text { agents }(\mathrm{mg} / \mathrm{L})^{c}\end{array}$} & \multirow[t]{2}{*}{ Other resistance patterns ${ }^{d}$} \\
\hline & & & & & & $\overline{\mathrm{CHL}}$ & FFC & CLR & TIA & VAL & $\overline{\text { LZD }}$ & \\
\hline TDP5 & S. cohnii & Pork & 1 & C & $P$ & 16 & $>64$ & $>64$ & 128 & 64 & 2 & OXA, CIP, GEN, ERY, TET \\
\hline TDPJC2 & S. cohnii & Chicken & 1 & $P$ & ND & 32 & 32 & $>64$ & 64 & 0.5 & 2 & OXA, CIP, ERY \\
\hline TYT5 & S. cohnii & Pork & 3 & $\mathrm{~F}$ & $P$ & 32 & 32 & 64 & 128 & 64 & 2 & TET \\
\hline TYT7 & S. cohnii & Pork & 3 & $\mathrm{~F}$ & $P$ & 16 & $>64$ & $>64$ & 64 & 16 & 2 & OXA, CIP, GEN, ERY \\
\hline TDP9 & S. equorum & Pork & 1 & $\mathrm{D}$ & $P$ & 32 & $>64$ & $>64$ & $>128$ & $>64$ & 8 & OXA, GEN, ERY, TET \\
\hline TDPJC9 & S. equorum & Chicken & 1 & j & P & 16 & 64 & $>64$ & 128 & 2 & 4 & OXA, GEN, ERY, TET \\
\hline TLD18 & S. equorum & Pork & 2 & L1 & $P$ & 16 & $>64$ & $>64$ & $>128$ & 64 & 8 & OXA, GEN, ERY, TET \\
\hline TLDJC5 & S. equorum & Chicken & 2 & L2 & $P$ & 64 & 32 & $>64$ & $>128$ & 16 & 4 & OXA, CIP, GEN, ERY, RIF, TET \\
\hline TLDJC9 & S. equorum & Chicken & 2 & N & $P$ & 32 & 64 & $>64$ & $>128$ & 2 & 4 & OXA, CIP, GEN, ERY, RIF, TET \\
\hline TLH5 & S. equorum & Pork & 4 & L3 & ND & 16 & $>64$ & $>64$ & 128 & 8 & 4 & OXA, CIP, GEN, ERY, TET \\
\hline TYTJC3 & S. equorum & Chicken & 3 & । & ND & 16 & 32 & $>64$ & $>128$ & 4 & 4 & ERY, TET \\
\hline TYTJC8 & S. equorum & Chicken & 3 & 1 & ND & 16 & 32 & 64 & 64 & 16 & 2 & OXA, CIP, GEN, ERY \\
\hline TDPJC13 & S. sciuri & Chicken & 1 & $E$ & P & 64 & 64 & $>64$ & $>128$ & 32 & 4 & OXA, CIP, GEN, TET \\
\hline TDPJC5 & S. sciuri & Chicken & 1 & $\mathrm{R}$ & ND & 32 & $>64$ & $>64$ & $>128$ & $>64$ & 16 & OXA, GEN, ERY, TET \\
\hline TLKJC2 & S. sciuri & Chicken & 6 & Q & $\mathrm{P}$ & 16 & $>64$ & $>64$ & $>128$ & 16 & 8 & OXA, CIP, GEN, ERY, TET \\
\hline TDP12 & S. simulans & Pork & 1 & A & ND & $>64$ & 64 & 64 & 64 & 16 & 4 & OXA, CIP, GEN, ERY, RIF \\
\hline TDP24 & S. simulans & Pork & 1 & B & ND & 32 & $>64$ & $>64$ & 64 & 2 & 4 & TET \\
\hline THTJC2 & S. simulans & Chicken & 5 & $\mathrm{O}$ & $P$ & 64 & 32 & $>64$ & $>128$ & 4 & 4 & OXA, CIP, GEN, ERY, RIF \\
\hline TLD12 & S. simulans & Pork & 2 & K & P & $>64$ & $>64$ & $>64$ & $>128$ & 64 & 8 & OXA, CIP, GEN, ERY, RIF, TET \\
\hline TLD20 & S. simulans & Pork & 2 & M & $P$ & $>64$ & $>64$ & $>64$ & 128 & 32 & 4 & OXA, CIP, GEN, ERY, RIF, TET \\
\hline TLD22 & S. simulans & Pork & 2 & G2 & $P$ & 16 & $>64$ & $>64$ & 128 & 8 & 8 & CIP, GEN, ERY, TET \\
\hline TYT6 & S. simulans & Pork & 3 & G1 & ND & 16 & $>64$ & $>64$ & $>128$ & 64 & 4 & OXA, ERY, TET \\
\hline Recipient RN4220 & S. aureus & & & & & 4 & 4 & 0.25 & 0.5 & 0.25 & 1 & ND \\
\hline RN4220-pHNLKJC2 & S. aureus & & & & & 32 & 64 & 16 & 16 & 8 & 4 & ND \\
\hline $\mathrm{DH} 5 \mathrm{a}$ & E. coli & & & & & 4 & 4 & - & - & - & - & ND \\
\hline $\mathrm{DH} 5 a-\mathrm{pUC18}-\mathrm{cfr}$ & E. coli & & & & & 8 & 8 & - & - & - & - & ND \\
\hline ATCC 29213 & S. aureus & & & & & 2 & 2 & 0.12 & 0.5 & 0.06 & 1 & \\
\hline
\end{tabular}

Patterns that differed from pattern A by six or more bands were considered to represent different strains. Patterns that differed by fewer than six bands were considered to represent subtypes within the main group (e.g.,L1, L2).

${ }^{\mathrm{b}} \mathrm{P}$, plasmid; ND, not determined.

${ }^{\mathrm{C}} \mathrm{CHL}$, chloramphenicol; FFC, florfenicol; CLR, clindamycin; TIA, tiamulin; VAL, valnemulin; LZD, linezolid. MIC was not measured because of known intrinsic resistance or naturally high $\mathrm{MICs}$.

${ }^{\mathrm{d}}$ The results were interpreted according to Eucast breakpoints (http://www.eucast.org/clinical_breakpoints/). OXA, oxacillin; CIP, ciprofloxacin; GEN, gentamycin; ERY, erythromycin; RIF, rifamycin; TET, tetracycline. All isolates were susceptible to vancomycin. ND, not determined.

found to be the predominant species of staphylococci in sausages and cheese samples [13-17]. S. equorum is used as one of the starter cultures in the preparation of smear-ripened cheese and cured meats such as sausages $[15,16]$. Since $S$. equorum present in retail meats has rare chances of coming in contact with antimicrobial agents, the origin and high prevalence of cfr in Staphylococcus equorum is intriguing.

The $c f r$-carrying segment (including rep, $\Delta p r e / m o b, c f r$, pre/mob and partial ermC) on the plasmid pHNLKJC2 from the chicken meat strain S. sciuri TLKJC2, was found to be similar to the corresponding plasmid regions from different staphylococcal species such as the plasmid pSS-03 (accession number JQ219851) from a bovine $S$. cohnii strain and the plasmid pMSA16 (accession number JQ246438) from a bovine MRSA ST9 strain in China (Figure 1B) [10,18]. In addition, this cfr-carrying segment also showed high nucleotide sequence identity (98\%) to the corresponding region of plasmid pSCFS1 (accession number AJ579365) from a bovine S. sciuri in Germany [19]. The cfr-carrying segment (including $\triangle \operatorname{tnp} A$ of $\operatorname{Tn} 558$, IS21-558; $\Delta \operatorname{tnpB}$; and tnpC of $\operatorname{Tn} 558, \operatorname{orf138}, f \operatorname{ex} A$ ) on the plasmid pHNTLD18 from the pork strain S. equorum TLD18 was identical to the corresponding segment of the 


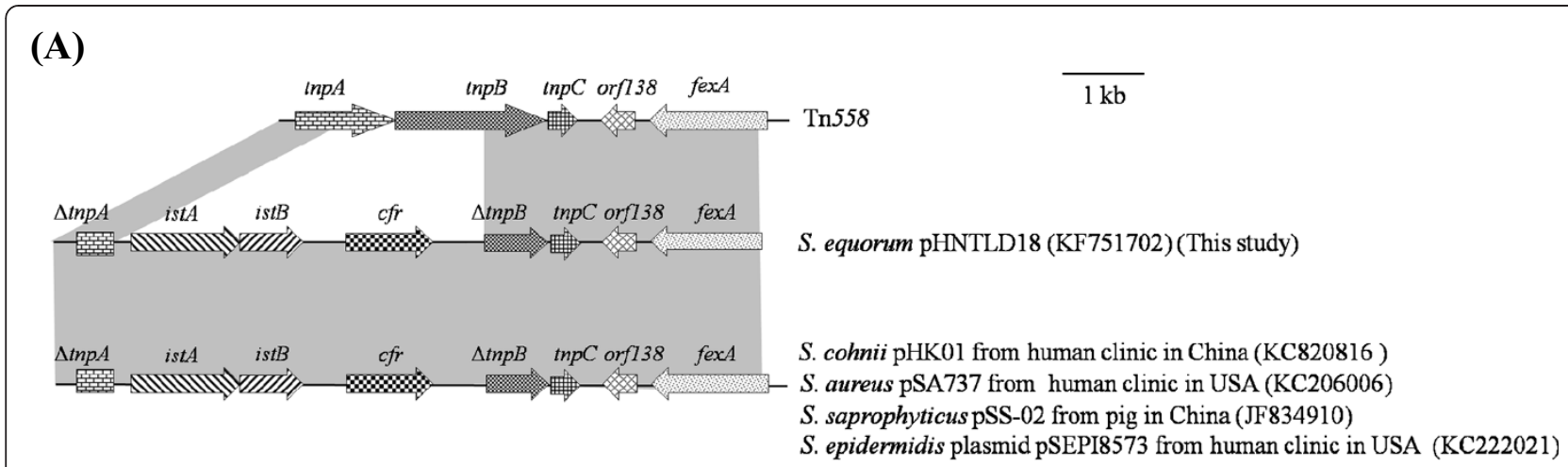

(B)

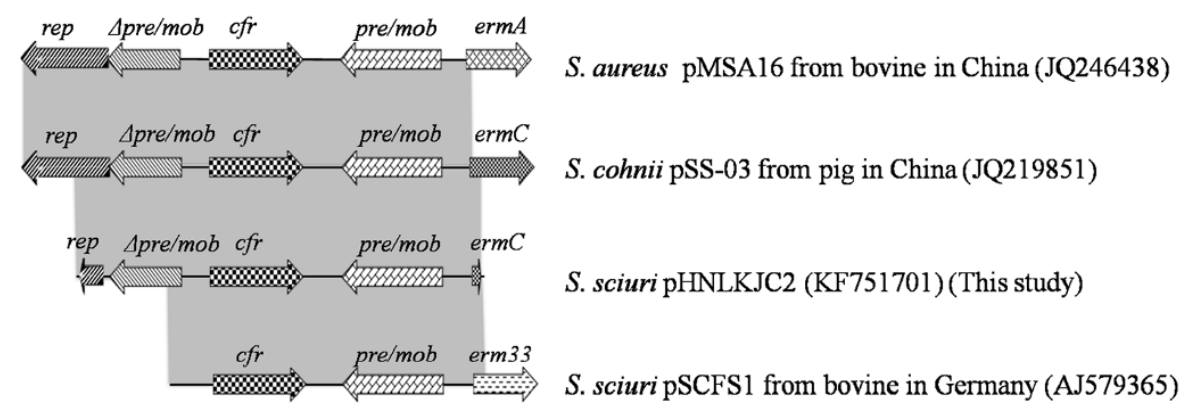

Figure 1 Genetic environment of cfr in plasmids pHNTLD18 and pHNLKJC2 and comparison with other similar plasmids. The arrows indicate the positions and directions of the transcription of the genes. Regions of $>98 \%$ homology are shaded in grey. $\Delta$ indicates a truncated gene. A. genetic environment of cfr in pHNTLD18; B. genetic environment of cfr in pHNLKJC2.

plasmid pHK01 (accession number KC820816) found in $S$. cohnii from human in China [20], the plasmid pSA737 (accession number KC206006) extracted from a human clinical MRSA strain and the plasmid pSEPI8573 (accession number KC222021) from a human clinical S. epidermidis strain in the United States [21], and the plasmid pSS-02 (accession number JF834910) obtained from a porcine $S$. saprophyticus strain in China(Figure 1A) [10]. These results indicated that the horizontal transfer mediated by mobile genetic elements such as plasmids and insertion sequences may contribute to the spread of $c f r$ and suggested that it is possible to transfer $c f r$ via mobile genetic elements from staphylococcal isolates of animal origin to the bacterial strains in the human body through meat consumption, posing a serious threat to the public health.

The MICs of the $c f r$-positive staphylococci indicated multiresistance phenotype in these strains other than the $\mathrm{PhLOPS}_{\mathrm{A}}$ phenotype, suggesting limited therapeutic options to control these $c f r$-carrying staphylococci. Most of the $c f r$-positive staphylococcal isolates showed low-level linezolid resistance with MIC values ranging from 4 to $16 \mathrm{mg} / \mathrm{L}$; this result is in agreement with previously reported linezolid MICs among cfr-carrying staphylococci from farm animals and humans $[10,11,22]$. In addition, five of the $c f r$-positive isolates had linezolid MIC values of $2 \mathrm{mg} / \mathrm{L}$, which is the same as the typical linezolid $\mathrm{MIC}_{90}$ value and not consistent with MIC value shifts observed for isogenic $c f r$-negative/positive staphylococcal strain pairs [23]. This finding indicated that $c f r$, although present, is not functional or is partially silenced in some way [24]. Although Staphylococcus strains isolated from meat samples showed low-level of linezolid resistance in the present study, emergence of the multiresistance gene $c f r$ in meat poses a potentially significant threat to the public health, considering that the cfr-mediated linezolid resistance can rapidly and widely spread among different bacterial species.

\section{Conclusions}

To the best of our knowledge, this is the first study to report a surprisingly high occurrence of $c f r$ in retail meat samples in Chinese markets. Animal meat harboring bacteria containing the transmissible $c f r$ would be a serious threat to the public health as these bacteria may act as reservoirs for spreading $c f r$ to bacteria that infect humans, particularly in environments with a large microbial community. Recently, $c f r$ was detected in human isolates in China [20,25]. Thus, more attention needs to be paid to the possibility that $c f r$ can find its way through the food chain to commensal or pathogenic bacteria of humans. Considering that a limited number of meat samples were used and that to from only one 
city in China, the results of the present study regarding dissemination of $c f r$ among staphylococcal species from animal food sources in China is not conclusive. Thus, continuing the surveillance of $c f r$ gene in meat distributed in China is critical to limit its dissemination, which could potentially threaten the human health.

\section{Methods}

Sample collection, identification of species, and cfr detection In February 2012, 72 pork samples and 46 chicken samples were collected from five free markets and one supermarket in Guangzhou. The meat samples were incubated in Luria-Bertani (LB) broth for enrichment. Then, the cultured broth was streaked onto selective media plates of Baird-Parker agar supplemented with $10 \mathrm{mg} / \mathrm{L}$ florfenicol. One isolate per sample was selected for further analysis. Whole-cell DNA was prepared according to a previously described protocol [26]. The presence of $c f r$ was screened by PCR with previously described primers [5]. Species identification of the $c f r$-carrying strains was performed by the API-Staph System (bioMérieux, France) and further confirmed by $16 \mathrm{~S}$ rRNA sequencing [27].

\section{Molecular typing and transformation}

PFGE of all cfr-positive Staphylococcus isolates was performed by using the CHEF Mapper System (Bio-Rad Laboratories, Hercules, CA), according to the previously described protocol [10]. All the plugs of genomic DNA were digested with SmaI (TaKaRa Biotechnology, Dalian, China). The PFGE patterns were interpreted according to the criteria described by Tenover et al. [28]. The location of $c f r$ was determined by Southern blotting.

Cfr-carrying plasmids of the isolates were extracted by using the QIAGEN Plasmid DNA Midi Kit (Qiagen, Hilden, Germany) and then transferred into S. aureus RN4220 by electrotransformation, as described previously [29]. The transformants were selected on media supplemented with $10 \mathrm{mg} / \mathrm{L}$ florfenicol, screened for cfr by PCR amplification, and confirmed by PFGE.

\section{Antimicrobial susceptibility testing}

The MIC values of all cfr-positive original Staphylococcus isolates and transformants were determined by the broth microdilution method, according to the recommendations specified in CLSI documents M100-S22 [30]. The results were interpreted according to Eucast breakpoints (http://www.eucast.org/clinical_breakpoints/). Isolates with an $\mathrm{MIC}$ of $\geq 16 \mathrm{mg} / \mathrm{L}$ were tentatively considered to be florfenicol-resistant [26]. The reference strain S. aureus ATCC 29213 was used for quality control.

\section{Cloning and sequencing of the regions flanking $\mathrm{cfr}$}

The regions flanking $c f r$ in the transformant obtained from the isolate TLKJC2 were determined by PCR mapping. The plasmid DNA of the isolate TLD18 was extracted and digested with EcoRI. The digested fragments were cloned into the pUC18 vector, and the recombinant plasmid (designated as pUC18-cfr) was introduced into Escherichia coli DH5 $\alpha$ with subsequent selection for the transformant (designated as E. coli DH5 $\alpha$ - pUC18-cfr) on media supplemented with $10 \mathrm{mg} / \mathrm{L}$ florfenicol. The approximately $5.7-\mathrm{kb}$ segment in pUC18-cfr, including $c f r$ and its flanking regions, was sequenced by primer walking. The DNA sequences were compared to those deposited in GenBank using the BLAST program (http://www.ncbi. nlm.nih.gov/BLAST).

\section{Nucleotide sequence accession number}

The nucleotide sequences of $c f r$-containing fragments of plasmids pHNLKJC2 and pHNTLD18 have been deposited in the GenBank under the accession numbers KF751701 and KF751702, respectively.

\section{Competing interests}

The authors declare that they have no competing interests.

\section{Authors' contributions}

$J H L, Z L Z$, and DCL conceived the study. HKW, JW, ZLZ, and XQL carried out the experiments, ZLZ, HKW, and WJ wrote the manuscript. JHL revised the manuscript. All authors have read and approved the final manuscript.

\section{Acknowledgements}

This work was supported in part by grants from National Key Basic Research Program of China (No. 2013CB127200), the Program for Changjiang Scholars and Innovative Research Team in University (No. IRT13063) and the fund for Training of PhD Students from the Ministry of Education of China (201044041100).

\section{Author details}

${ }^{1}$ College of Veterinary Medicine, National Reference Laboratory of Veterinary Drug Residues (SCAU), South China Agricultural University, Guangzhou, China. ${ }^{2}$ Department of Applied Biology and Chemical Technology, The Hong Kong Polytechnic University, Hong Kong, China.

Received: 18 February 2014 Accepted: 30 May 2014

Published: 9 June 2014

\section{References}

1. Bozdogan B, Appelbaum PC: Oxazolidinones: activity, mode of action, and mechanism of resistance. Int J Antimicrob Agents 2004, 23:113-119.

2. Shaw KJ, Barbachyn MR: The oxazolidinones: past, present, and future. Ann NY Acad Sci 2011, 1241:48-70.

3. Kehrenberg C, Schwarz S, Jacobsen L, Hansen LH, Vester B: A new mechanism for chloramphenicol, florfenicol and clindamycin resistance: methylation of 23S ribosomal RNA at A2503. Mol Microbiol 2005, 57:1064-1073.

4. Long KS, Poehlsgaard J, Kehrenberg C, Schwarz S, Vester B: The Cfr rRNA methyltransferase confers resistance to phenicols, lincosamides, oxazolidinones, pleuromutilins, and streptogramin A antibiotics. Antimicrob Agents Chemother 2006, 50:2500-2505.

5. Smith LK, Mankin AS: Transcriptional and translational control of the mlr operon, which confers resistance to seven classes of protein synthesis inhibitors. Antimicrob Agents Chemother 2008, 52:1703-1712.

6. Schwarz S, Werckenthin C, Kehrenberg C: Identification of a plasmid-borne chloramphenicol-florfenicol resistance gene in Staphylococcus sciuri. Antimicrob Agents Chemother 2000, 44:2530-2533. 
7. Wang Y, Li D, Song L, Liu Y, He T, Liu H, Wu C, Schwarz S, Shen J: First report of the multiresistance gene cfr in streptococcus suis. Antimicrob Agents Chemother 2013, 57:4061-4063.

8. Shen J, Wang Y, Schwarz S: Presence and dissemination of the multiresistance gene cfr in Gram-positive and Gram-negative bacteria. J Antimicrob Chemother 2013, 68:1697-1706.

9. Liu Y, Wang Y, Schwarz S, Li Y, Shen Z, Zhang Q, Wu C, Shen J: Transferable multiresistance plasmids carrying cfr in Enterococcus spp. from swine and farm environment. Antimicrob Agents Chemother 2013, 57:42-48.

10. Wang Y, Zhang W, Wang J, Wu C, Shen Z, Fu X, Yan Y, Zhang Q, Schwarz S, Shen J: Distribution of the multidrug resistance gene cfr in Staphylococcus species isolates from swine farms in China. Antimicrob Agents Chemother 2012, 56:1485-1490.

11. Wang Y, He T, Schwarz S, Zhao Q, Shen Z, Wu C, Shen J: Multidrug resistance gene $c f r$ in methicillin-resistant coagulase-negative staphylococci from chickens, ducks, and pigs in China. Int J Med Microbiol 2013, 303:84-87.

12. LaMarre JM, Locke JB, Shaw KJ, Mankin AS: Low fitness cost of the multidrug resistance gene cfr. Antimicrob Agents Chemother 2011, 55:3714-3719.

13. Schleifer KH, Kilpper Baltz R, Devriese LA: Staphylococcus arletae sp.nov., S. equorum sp. nov. and S. kloosii sp. nov.: three new coagulase-negative, novobiocin-resistant species from animals. Syst Appl Microbiol 1984, 5:501-509.

14. Corbière Morot-Bizot S, Leroy S, Talon R: Staphylococcal community of a small unit manufacturing traditional dry fermented sausages. Int J Food Microbiol 2006, 108:210-217.

15. Mauriello G, Casaburi A, Blaiotta G, Villani F: Isolation and technological properties of coagulase negative staphylococci from fermented sausages of Southern Italy. Meat Sci 2004, 67:149-158.

16. Bockelmann W: Development of defined surface starter cultures for the ripening of smear cheeses. Int Dairy J 2002, 12:123-131.

17. Irlinger F, Morvan A, El Solh N, Bergere JL: Taxonomic characterization of coagulase-negative staphylococci in ripening flora from traditional French cheeses. Syst Appl Microbiol 1997, 20:319-328.

18. Wang X, Zhang W, Schwarz S, Yu S, Liu H, Si W, Zhang R, Liu S: Methicillin-resistant Staphylococcus aureus ST9 from a case of bovine mastitis carries the genes $\mathrm{cr}$ and erm (A) on a small plasmid. J Antimicrob Chemother 2012, 67:1287-1289.

19. Kehrenberg C, Ojo KK, Schwarz S: Nucleotide sequence and organization of the multiresistance plasmid pSCFS1 from Staphylococcus sciuri. $J$ Antimicrob Chemother 2004, 54:936-939.

20. Chen H, Wu W, Ni M, Liu Y, Zhang J, Xia F, He W, Wang Q, Wang Z, Cao B: Linezolid-resistant clinical isolates of enterococci and Staphylococcus cohnii from a multicentre study in China: molecular epidemiology and resistance mechanisms. Int J Antimicrob Agents 2013, 42:317-321.

21. Mendes RE, Deshpande LM, Bonilla HF, Schwarz S, Huband MD, Jones RN, Quinn JP: Dissemination of a pSCFS3-like cfr-carrying plasmid in Staphylococcus aureus and Staphylococcus epidermidis Clinical Isolates Recovered from Hospitals in Ohio. Antimicrob Agents Chemother 2013, 57:2923-2928

22. Mendes RE, Hogan PA, Streit JM, Jones RN, Flamm RK: Zyvox(R) Annual appraisal of potency and spectrum (ZAAPS) program: report of linezolid activity over 9 years (2004-12). J Antimicrob Chemother 2014, 69:1582-1588.

23. Locke JB1, Morales G, Hilgers M, GC K, Rahawi S, Jose Picazo J, Shaw KJ, Stein JL: Elevated linezolid resistance in clinical cfr-positive Staphylococcus aureus isolates is associated with co-occurring mutations in ribosomal protein L3. Antimicrob Agents Chemother 2010, 54:5352-5355.

24. Liu Y, Wang Y, Schwarz S, Wang S, Chen L, Wu C, Shen J: Investigation of a multiresistance gene $\mathrm{cfr}$ that fails to mediate resistance to phenicols and oxazolidinones in Enterococcus faecalis. J Antimicrob Chemother 2014, 69:892-898

25. Cui L, Wang Y, Li Y, He T, Schwarz S, Ding Y, Shen J, LV Y: Cfr-mediated linezolid-resistance among methicillin-resistant coagulase-negative staphylococci from infections of humans. PLoS One 2013, 8:e57096.

26. Kehrenberg C, Schwarz S: Distribution of florfenicol resistance genes fexA and cfr among chloramphenicol-resistant Staphylococcus isolates. Antimicrob Agents Chemother 2006, 50:1156-1163.

27. Kim TW, Kim SE, Park CS: Identification and distribution of Bacillus species in doenjang by whole-cell protein patterns and 16S rRNA gene sequence analysis. J Microbiol Biotechnol 2010, 20:1210-1214.
28. Tenover FC, Arbeit RD, Goering RV, Mickelsen PA, Murray BE, Persing DH, Swaminathan B: Interpreting chromosomal DNA restriction patterns produced by pulsed-field gel electrophoresis: criteria for bacterial strain typing. J Clin Microbiol 1995, 33:2233-2239.

29. Schenk S, Laddaga RA: Improved method for electroporation of Staphylococcus aureus. FEMS Microbiol Lett 1992, 94:133-138.

30. CLSI: Performance Standards for Antimicrobial Susceptibility Testing; Twenty-Second Informational Supplement, CLSI document M100-S22. Wayne, PA: Clinical and Laboratory Standards Institute; 2012.

doi:10.1186/1471-2180-14-151

Cite this article as: Zeng et al:: High prevalence of Cfr-producing

Staphylococcus species in retail meat in Guangzhou, China. BMC Microbiology 2014 14:151.

\section{Submit your next manuscript to BioMed Central and take full advantage of:}

- Convenient online submission

- Thorough peer review

- No space constraints or color figure charges

- Immediate publication on acceptance

- Inclusion in PubMed, CAS, Scopus and Google Scholar

- Research which is freely available for redistribution

Submit your manuscript at www.biomedcentral.com/submit
C) Biomed Central 